\title{
PRESENT TREND IN EVENINGNESS AMONGST MEDICAL STUDENTS IN THE EAST
}

1. MBBS, MCPS

Associate Professor

Department of Community Medicine

Dow International Medical College,

Ojha Campus

Dow University of Health Sciences

Karachi

2. MBBS

3. MBBS, MPH, MES

Assistant Professor

Department of Community Medicine

Dow International Medical College,

Ojha Campus

Dow University of Health Sciences Karachi

Correspondence Address:

Dr. Surriya Jabeen

B-100, Block W North Nazimabad

Karachi-47700

fmddimc@gmail.com

Article received on:

16/12/2014

Accepted for publication:

05/01/2015

Received after proof reading:

$17 / 04 / 2015$

\section{Dr. Surriya Jabeen ${ }^{1}$, Dr. Aneesa Matloob ${ }^{2}$, Dr. Syed Mohammad Maqsood ${ }^{3}$}

\begin{abstract}
Objectives: To analyze individual preference in organizing their behavior within 24 hours(Human chronotypes) also referred to as morningness/ eveningness. Setting: Dow Medical College, Dow university of Health Sciences Karachi. Period: From September 2012 to December 2013. Study Design: Cross-sectional. Methods: Subjects (Medical students) from first semester to final semester were invited to participate in this study, A total of 710 subjects were included. Their demographic data such as age, gender was obtained. Instrument is an integrated questionnaire (Horne JA and Ostberg O Morningness- Eveningness questionnaire MEQ original 1976) designed to assess chronotype of young adult population. Results: Out of different existing chronotypes, biggest group which dominated the current study was intermediate type. Conclusions: Present study determined, chronotype of young population (medical students) of this region. The assessment of individual chronotype is important not only for the diagnosis and treatment of sleep disorders, additionally to evaluate ability to adapt for specific work schedule.
\end{abstract}

Key words: Morningness eveningness, Circadian rhythm, Chronotype, diurnal preference, Biological clock.

Article Citation: Jabeen S, Matloob A, Maqsood SM. Present trend in eveningness amongst medical students in the East. Professional Med J 2015;22(4):495-499.

\section{INTRODUCTION}

The primary need on evolution of human behavior is the need to explore resources which necessitate time perception. To avail these resources, when supplies are available at around constant time of the day a time keeping system may be required to adapt behavior to daily availability of resources this is the model behind certain studies ${ }^{1,2}$. Subsequently this concept progressed and the role of fundamental oscillator Supra chiasmatic nucleus (SCN)in the mammalian circadian rhythm system with multiple signals working internally and externally that maintain the circadian of sleep wakefulness broadened ${ }^{3,45}$. Owing to rotation of earth around its own orbit, time keeping system of the body is exposed to daily changes in light intensity. Sleep wake rhythm city in the human body is controlled by a complex interplay of endogenous clocks regulating the transition between dark/light cycle. Human display wide inter individual difference in organizing their daily activities within 24 hours / day, this is appreciated in their preferred timing of sleep and wake fullness. SCN which institute internal biologic clock located above the crossing of optic nerve, not only modulate daily rhythm of sleep wake cycle but also the rhythm of core body temperature and secretion of certain hormones such as melatonin, cortisol $\left.\right|^{6,7}$. This along with a sleep homeostasis placed exterior to the human body, Zeitgeber, which include natural lighting ,exercise and social contacts maintain daily sleep wake cycle ${ }^{8,9}$. The retinal output is transduced to SCN where they synchronized daily biological rhythm generated by SCN to exactly 24 hours through its output signals. The SCN coordinate with all the cellular circadian clocks just as circadian expression of ion channels, throughout the body's tissue. An individual preference in rhythmic design of time keeping that is potentially significant to understanding is the degree to which individual prefer organizing their activities 
closer to the morning or evening. Based on diurnal preference or morningness eveningness people can be divided in to chronotype i.e lark and owls with demonstrated difference in sleep wake pattern ${ }^{10,11}$.

Dynamic of sleep homeostasis always remained focus of attention for researchers, most of these studies based on this observations were conducted in western countries. We speculate that might have been influenced by the cultural differences and acceptability, therefore generalizing previous finding to east might not be appropriate.

The aim of this study was to address individual difference in circadian phase preference of this region and identify the chronotype of young population.

\section{MATEIAL AND METHODS}

It was a cross sectional study which was carried out at Dow Medical College from September 2012 to December 2013. It took us four months to analyze the data. The study was approved by the institutional review board of Dow University of Health Sciences Karachi. Participants included were healthy medical students from first semester to final semester with clear Health examination labs which is mandatory for admission in to this university. Data was collected from all those subjects who were willing and fit to participate. Their demographic information including age, gender, was documented. Out of 1000, a random sample of 710 voluntarily consented to participate in the study, written and informed consent was obtained. Screening tool has a set of scale based on scoring criteria. The measuring scale having a range from 16 to 86 . Where high ratings signify morningness, low rating suggest an evening preference (Original Horne JA and Ostberg O criteria).Participants were asked to completely fill Morning Evening questionnaire (MEQ). This $M E Q$ was initially given to a sample of 20 students to assess the data gathering process. This questionnaire is still the most widely used tool to diagnose circadian typology of young population between 18-32years of age ${ }^{12}$. This questionnaire included 19 items reflecting the habitual rising and bed times, preferred times of physical and mental performance and subjective alertness after rising and before going to sleep. The questionnaire was distributed in the class room in the presence of investigator with the help of teachers. Participants with any active disease or any kind of addiction were asked not to fill the questionnaire. A brief introduction of the questionnaire and explanation was provided.

(Horne JA and Ostberg O Scoring criteria:)

- $\quad$ Definitely Morning Type 70-86

- Moderately morning Type 59-69

- Neither Type 42-58

- Moderately Evening Type 31-41

- Definitely Evening Type 16-30

\section{RESULTS}

All data analysis was carried out on statistical Package for social science(SPSS $V$ 20) for windows .Quantitative variable were presented by their mean $\pm S D$ values, however, the qualitative variables were presented by frequency and percentages. A total of 710 completely filled questionnaires were returned.Response rate was $71.0 \%$. Most of the subjects in the current study were females. There were 608 (85.63\%) females and $102(14.37 \%)$ males. The mean age was $20.08 \pm 1.933$. Table-l. Present the numbers and percentage of different chronotypes evidenced in this study. Prevalence of eveningness was not observed in this study instead the biggest group was the intermediate chronotype. Figure 1. depict the prevalence of different chronotypes. Present study demonstrated 179(25.2\%) evening chronotype which included both moderately plus definitely evening type individuals. Morning chronotype that comprised both moderately morning and defininitely morning type were 228(32.1\%), however, largest group was intermediate or neither type 303(42.7\%) and the next large group of this study was morning type. The distribution of MEQ score was ranging from minimum 22 and maximum 87, Mean $51.39 \pm$ $10.40 \mathrm{SD}$, median was 52 . Interquartile range was 15 and mode was 56. 


\begin{tabular}{|c|c|c|}
\hline \multicolumn{3}{|c|}{ Score Category } \\
\hline & Frequency & Percent\% \\
\hline DM & 24 & 3.4 \\
\hline MM & 204 & 28.7 \\
\hline Intermediate & 303 & 42.7 \\
\hline ME & 159 & 22.4 \\
\hline $\mathrm{DE}$ & 20 & 2.8 \\
\hline Total & 710 & 100 \\
\hline \multicolumn{3}{|c|}{$\begin{array}{cc}\text { DM (definitely morning ) } & M M \text { (Moderately Morning } \\
M E \text { (Moderately evening) } & D E \text { (Definitely Evening) }\end{array}$} \\
\hline
\end{tabular}

\section{score category}

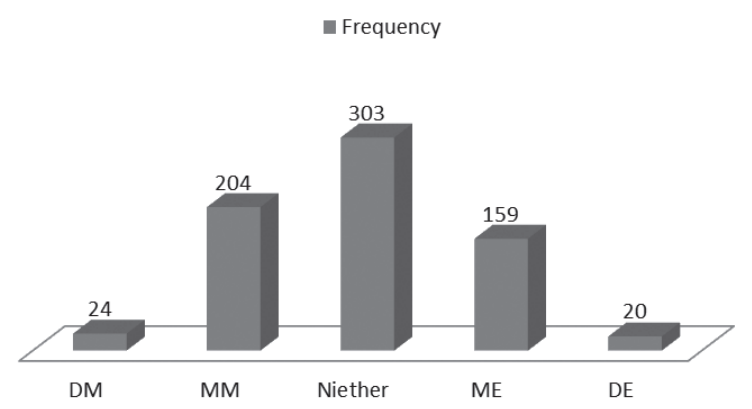

\section{DISCUSSION}

It was observed that our results were supporting intermediate chronotype amongst young adults in the present study, which has emerged as the largest group in the current study. Compare to the earlier studies conducted in the west which documented an increase eveningness in young population of college students. ${ }^{13,14,15}$ The next large group of this study was morning type which has made a difference in this study as compare to the studies mostly conducted in the western world. Present result was similar to another research from Middle East where no particular trend was observed in university students rather intermediate typology "neither type" was evidenced. Geographical location of the region, studied in that particular research was seemingly that the individuals were exposed to intense light in that area $^{16}$. Emerging knowledge of sleep system in studies from different parts of the world have increased the awareness of the prevalence of sleep disorders and its management with different techniques, one of which is bright light therapy. Bright light therapy has now become a successful approach to realign the circadian phase, because age is predictor of many sleep wake parameters, childhood sleep issues such as bed time resistance delayed sleep latency, get up time are often seen but little is known about the distribution of chrontype in prepubertal children (jenni et al 2005, Owens 2007). Human body simultaneously is under the influence of three clocks, two are related to solar and biological cycle, and the third clock is related to social time. Biological cycle which is the product of an endogenous rhythm within the body. Time zones were invented to adjust the constant changing solar time, but they are only estimation as a result sun rises and sets at variable social times within each time zone for instance this divergence exist in China where one sixth of the Earths circumference stays on Peking time officially. This difference in solar and social time is widened in western china to an extent that the individual do not set their routine according to official time ${ }^{17}$. Proximate studies in the west demonstrated morning preference in the older population however it was evidenced that amount of time these subjects spent in various light exposure threshold levels was different, analysis revealed that the older subjects spent a significantly greater amount of their waking day in light, and they were of the opinion that the differences in natural light exposure contributed to the age related phase advance of the circadian pacemaker and its later timing relative to the sleep-wake cycle ${ }^{18}$. Though the Genetic approach had provided a different window and supported circadian consistency and preference was rooted in human DNA. ${ }^{19}$ Light and temperature signals entrain the clock mechanism to set the circadian phase, which describes the timing of endogenous rhythms relative to the environmental cycle (Bell-Pedersen et al, 2005), based on available experimental data, detailed computerized models has been considered for circadian rhythm in Drosophilia different models showed how regulatory feedback loops in the circadian genetic network cooperate to produce sustained oscillation in continuous darkness. ${ }^{2}$ Incorporating the effect of light in to these model account for phase shift induced by light pulses for the entrainment of the circadian clock. 


\section{CONCLUSIONS}

Studies are desired to ascertain the chronotypes of young population in diverse geographical meridian to assess regional topographic specificity. The evaluation of individual chronotype is important for the diagnosis and treatment of sleep disorders.

\section{ACKNOWLEDGEMENT}

Author is grateful to the Medical statistician Mr Bukhtiar Alam Assistant Professor Statistics Government College of Commerce and Economics 2 Karachi for his assistance in data analysis.

\section{Copyright(C) 05 Jan, 2015.}

\section{REFERENCE}

1. Crystal $D$ j. Theoretical and conceptual issues in time -place discrimination. Eur J Neurosci.2009;9: 17561766.

2. R A Hut, Beersma. M.G. Evolution of time keeping mechanism:early emergence and adaptaion to photoperiid. Phil.Trans.R.Soc.B .2011;2141-2154.

3. Dijk D J, Lockly S W. Functional Genomic of sleep and circadian Rhythm Invited Review : Integration of human sleep -wake regulation and circadian rhythmicity. J Appl Phsiol. 2002; 92: 852-862.

4. Deboer T, Steensel J M, Detari L, Meiger H J. Sleep state alter activity of suprachaismatic nucleus neuron. Nature neuroscience. 2003; 6:1086-1990.

5. Lincolin $G$,Messager $S$, Anderson $H$, Hazlerigg $D$. Temporal expression of seven clock gene in the supra chiasmic nucleus and the pars tuberalis of the sheep : evidence for an intenal conincidence timer. Proc NatlAcad Sci Usa .2002; (21):13890-13895.

6. Fisher S, Smolnik R, Herm M et al. Melatonin acutely improve the Neuroendocrine Architecture of sleep in blind individuals. J clin Endocrinol Metab. 2003;88:5315-5320.

7. Kayumov $L$, Brown $G$, Jindal $R$ et al. A randomized, Double -Blind ,Placebo- controlled cross over study of the Effect of exogenous Melatonin on Delayed sleep Phase Syndrome. Psychosomatic Medicine. 2001;63:40-48.
8. J Waterhouse Jet-lag and shift work: (1) circadian rhythms. J R Soc Med. 1999;92:398-401.

9. Nakade M, Takeuchi H, Kurotani M, et al. Effects of meal Habits and Alcohol /cigarette consumption on Morning ness -evening ness preference and sleep habits by Japanese Female students aged 18-29. J Phsiol Anthropol. 2009; 83-90.

10. Biss K Renee , Hasher L. Happy as lark: morning Type Younger and Older adults are higher in positive effect. Emotion.2012;12(3):437-441.

11. Sack R; Auckley D; Auger RR et al. Circadian Rhythm sleep Disorder : Part 1 Basic principles, Shift work and jet lag Disorders An American academy of sleep Medicine Review. Sleep. 2007; 30: 1460-1483.

12. J.A Horne, O. Ostberg. A self-Assessment Questionnaire to determine morningness eveningness in Human Circadian Rhythms. International journal of chronobiology .1976;4:97-110.

13. Cung $K F$, Cheung $M M$. Sleep wake pattern and Sleep Disturbance among Hong Kong Chinese Adolescents. Sleep 2008Feb 1;31(2):185-194.

14. Brown, Franklin C,Soper, Barlow et al. Prevalence of Delayed Sleep phase syndrome in university students. College student journal ; 2001;35 : 472-475.

15. Carskadon A M, Acebo C, Richardson S G. An approach to studying Circadian Rhythms of Adolescent Humans. Journal of Biological Rhythm , 1997; 12(3):278-289.

16. BaHammam S.A,Almestehi $W$,Albatli et al. Distribution of chronotype in a large sample of young adults Saudis. Ann Saudi Med. 2011;31(2):183-186.

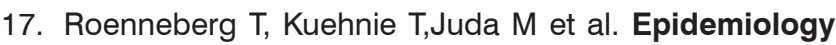
of the human circadian clock. Sleep Medicine .2007;11:429-438.

18. Scheuermaier K, Laffan M A, Duffy F J. Light exposure patterns in healthy older and young adults. J Biol Rhythms. 2010 April ; 25(2): 113-122.

19. Leloup C J, Goldbeter A. Modeling the circadian clock: from molecular mechanism to physiological disorders. BioEssay. 2008;30:590-600.

20. Sheeba V, Kaneko M, Sharma K V et al. The drosophila circadian pace maker circuit : pasdeux or Tarantella . Crit Rev Biochem Mol Biol. 2008; 43:37-61. 


\section{"Fools are without number."}

\section{Desiderius Erasmus}

\section{AUTHORSHIP AND CONTRIBUTION DECLARATION}

\begin{tabular}{|c|l|c|c|}
\multicolumn{4}{|c|}{ AUTHORSHIP AND CONTRIBUTION DECLARATION } \\
\hline Sr. N. & \multicolumn{1}{|c|}{ Author-s Full Name } & Contribution to the paper & Author=s Signature \\
\hline 1 & Dr. Surriya Jabeen & Main author & Currig Jateren \\
2 & Dr. Aneesa Matloob & Co-author \\
3 & Dr. Syed Mohammad Maqsood & Co-author \\
\hline
\end{tabular}

